\title{
Uso de Substrato Compostado na Produção de Mudas de Eucalyptus dunnii e Cordia trichotoma
}

\author{
Clovis Orlando Da Ros ${ }^{1}$, Franciel Eduardo Rex ${ }^{2}$, Isadora Rangel Ribeiro ${ }^{2}$, \\ Pâmela Suélen Kafer ${ }^{2}$, Alexandre Couto Rodrigues ${ }^{1}$, Rodrigo Ferreira da Silva ${ }^{1}$, \\ Lucindo Somavilla ${ }^{1}$
${ }^{1}$ Departamento de Ciências Agronômicas e Ambientais, Universidade Federal de Santa Maria - UFSM, Frederico Westphalen/RS, Brasil
${ }^{2}$ Departamento de Engenharia Florestal, Universidade Federal de Santa Maria - UFSM,
Frederico Westphalen/RS, Brasil

\begin{abstract}
RESUMO
Os substratos apresentam influência na germinação e no crescimento de mudas de espécies florestais. Com o objetivo de avaliar a germinação, o crescimento e a qualidade de mudas de Eucalyptus dunnii e Cordia trichotoma em substratos obtidos pela compostagem de resíduos orgânicos foi conduzido um experimento na UFSM, campus de Frederico Westphalen, Brasil. Foram usados quatro substratos de compostagem (resíduos de restaurante universitário, resíduos de reciclagem de lixo domiciliar, dejeto líquido de bovinos e lodo do processo de flotação) e um substrato comercial (com e sem fertilizante mineral). O delineamento foi inteiramente casualizado com quatro repetições. Os substratos influenciaram na velocidade de germinação, mas não afetaram o percentual final de germinação. Os substratos alternativos provenientes de resíduos de restaurante universitário e do lodo de processo de flotação proporcionaram maior altura e diâmetro de colo das mudas E. dunnii e C. trichotoma e podem ser usados em substituição ao substrato comercial.
\end{abstract}

Palavras-chave: resíduos orgânicos, fertilizante mineral, espécies florestais.

\section{Composted Substrate in the Production of Eucalyptus dunnii and Cordia trichotoma Seedlings}

\begin{abstract}
The substrates have influence on germination and growth of forest species seedlings. Aiming to evaluate the germination, growth and quality of Eucalyptus dunnii and Cordia trichotom seedlings on substrates obtained by composting of organic waste we conducted an experiment at UFSM, campus Frederico Westphalen, Brazil. Four substrates composting (university restaurant waste, recycling household waste, liquid cattle manure and flotation process sludge) and commercial substrate (with and without mineral fertilizer) were used. The design was completely randomized with four replications. The substrates influenced the germination rate, but did not affect the final germination percentage. Alternative substrates from waste of university restaurant waste and flotation process sludge provided greater height and diameter of E. dunni and C. trichotoma seedlings and can be used to replace the commercial substrate.
\end{abstract}

Keywords: organic waste, mineral fertilizer, forest species. 


\section{INTRODUÇÃO}

O sucesso dos projetos de reflorestamentos, seja para fins comerciais ou conservacionistas, depende da escolha da espécie florestal (Cunha et al., 2005) e da definição de métodos e de estratégias que permitam a produção de mudas de qualidade em curto período de tempo (Correia et al., 2005). Uma das dificuldades enfrentadas na produção de mudas é o crescimento lento apresentado por muitas espécies florestais. Em face disso, torna-se importante a definição de estratégias que favoreçam a sua produção com qualidade e em menor tempo.

O Eucalyptus dunnii é uma espécie exótica da família Myrtaceae, originário da região de CoffsHarbour, nordeste de New South Wales e sul de Queensland, na Austrália, com rápido crescimento inicial das mudas (EMBRAPA, 1988). O Cordia trichotoma (louro-pardo) é uma espécie nativa pertencente à família Boraginaceae, que ocorre desde o Nordeste até o Sul do Brasil, com crescimento inicial lento a moderado (Carvalho, 2002). As duas espécies são adaptadas ao Sul do Brasil e com potencial de utilização em plantações florestais com fins econômicos (Scheeren et al., 2002; Paludzyszyn et al., 2006). No entanto, o crescimento inicial no campo e a produção de madeira dependem da qualidade da muda produzida no viveiro florestal, onde o substrato é um dos principais fatores de interferência na germinação, crescimento e qualidade das mudas (Cunha-Queda et al., 2010). Usando 14 substratos renováveis de diferentes combinações de materiais orgânicos, Kratz \& Wendling (2013) encontraram variação de 6,4 até $16,0 \mathrm{~cm}$ na altura de mudas do E. dunnii. Essa variação pode estar relacionada à densidade, à aeração, à capacidade de retenção de água, à disponibilidade de nutrientes, ao $\mathrm{pH}$ e à relação $\mathrm{C} / \mathrm{N}$ do substrato (Abad et al., 2005).

Os atributos físicos e químicos são fundamentais para a qualidade do substrato e a adequação é possível com a mistura de resíduos orgânicos, porém o crescimento e a qualidade das mudas nos viveiros florestais podem variar em função das espécies florestais (Cunha-Queda et al., 2010; Gonçalves et al., 2014). Em um estudo com duas espécies florestais, Melo et al. (2014) encontraram aumento do crescimento de mudas de E. grandis e diminuição nas mudas da candeia (Eremanthus erythropappus) com combinações de esterco de curral curtido em casca de arroz carbonizada e fibra de coco. Por essas razões, substratos alternativos provenientes de resíduos orgânicos devem ser estudados, visando disponibilizar maior quantidade de nutrientes, reduzir o custo de produção e aumentar a qualidade das mudas em viveiros florestais (Sturion \& Antunes, 2000). Além disso, o uso adequado de resíduos orgânicos disponíveis na região pode minimizar o risco de contaminação ambiental e contribuir para a produção de substratos alternativos em substituição ao substrato comercial (Gomes et al., 2008).

$\mathrm{Na}$ escolha do substrato deve-se caracterizar primeiramente o material, determinando-se seus atributos físicos, químicos e biológicos e, posteriormente, compará-lo com um substrato considerado "ideal", ajustando suas características, se necessário, e, finalmente, avaliar em ensaios de crescimento vegetal (Abad et al., 1992). Além disso, o tipo de recipiente interfere na qualidade das mudas e no custo de produção (Kostopoulou et al., 2011). Atualmente, o tubete é o recipiente mais utilizado para mudas florestais (Wendling \& Dutra, 2010) e nesse sistema de produção, as características físicas do substrato são fundamentais para o equilíbrio dos seus constituintes, de forma a prover uma adequada relação entre macro e microporosidade (Lopes et al., 2005).

Com bases nestas informações, o objetivo do trabalho foi avaliar a germinação, o crescimento e a qualidade de mudas de E.dunnii e C. trichotoma em diferentes substratos provenientes da compostagem de resíduos orgânicos.

\section{MATERIAL E MÉTODOS}

O experimento foi conduzido em casa de vegetação, no Viveiro Florestal da Universidade Federal de Santa Maria, campus de Frederico Westphalen, RS, localizado na latitude de $27^{\circ} 23^{\prime} 46^{\prime \prime}$ Sul e longitude de $53^{\circ} 25^{\prime} 37^{\prime \prime}$ Oeste. O clima é subtropical úmido com verão quente, tipo $\mathrm{Cfa}$, com máximas maiores ou iguais $22{ }^{\circ} \mathrm{C}$ e mínimas dos meses mais frios entre -3 e $18^{\circ} \mathrm{C}$, e com precipitação média anual entre 1.900 e $2.200 \mathrm{~mm}$ (Alvares et al., 2013).

O delineamento experimental foi o inteiramente casualizado com quatro repetições, no esquema fatorial $2 \times 6$ : duas espécies florestais (E. dunnii e $C$. trichotoma) e seis substratos, sendo quatro obtidos 
pela compostagem de resíduos orgânicos (RRU, RLD, DLB e LPF), conforme descritos na Tabela 1, e um, de substrato comercial (SC), com e sem fertilizante mineral. O SC utilizado foi o Hortaliça H. Decker ${ }^{\circledR}$ e o fertilizante mineral foi o Osmocote ${ }^{\circledR}$ (15-09-12) na dose equivalente a $4,5 \mathrm{~kg} \mathrm{~m}^{-3}$, aplicado individualmente por tubete. Nos substratos oriundos da compostagem não foram aplicados fertilizantes minerais.

A compostagem dos resíduos orgânicos foi realizada em pilhas de compostagem, montadas no formato cônico, com diâmetro médio de $1,2 \mathrm{~m}$ e $1,1 \mathrm{~m}$ de altura, com camadas alternadas de resíduo orgânico com baixa relação $\mathrm{C} / \mathrm{N}$ ( $30 \%$ do volume) e camadas de resíduo orgânico de alta relação $\mathrm{C} / \mathrm{N}$ (70\% do volume), conforme materiais descritos na Tabela 1.

As pilhas de compostagem foram umedecidas e revolvidas periodicamente até o final do processo de compostagem, que ocorreu em 120 dias, avaliada pelo teste de maturação, descrito em Oliveira et al. (2008). Em cada pilha de compostagem foram coletadas amostras através da técnica de quarteamento, conforme a NBR 10.007 (ABNT, 2004), secadas à temperatura de $65^{\circ} \mathrm{C}$, trituradas, homogeneizadas e determinado o $\mathrm{pH}$ em água, nitrogênio total por digestão úmida com ácido sulfúrico (método Kjeldahl), carbono orgânico por oxidação com dicromato de potássio (método Walkey Black), fósforo e potássio extraíveis pelo método Mehlich-1, cálcio e magnésio trocáveis, e nitrogênio mineral com extração salina de $\mathrm{KCl}\left(1,0 \mathrm{~mol} \mathrm{~L}^{-1}\right)$, conforme metodologia descrita em Tedesco et al.
(1995), e densidade aparente pelo método da proveta (EMBRAPA, 1997). Na Tabela 2 estão relacionados os atributos químicos e físicos dos substratos.

A semeadura das espécies florestais foi realizada em 15/10/2012, em tubetes de $100 \mathrm{~cm}^{3}$ para o E. dunnii e de $170 \mathrm{~cm}^{3}$ para C. trichotoma, usando-se duas sementes por tubete e, após a estabilização da germinação, foi mantida apenas uma plântula. Foram usados oito tubetes por repetição na produção de mudas de E. dunnii e nove tubetes para o C. trichotoma. Durante o período de cultivo das mudas foram utilizadas irrigações diárias por aspersão, com lâmina de $12 \mathrm{~mm}$ diários, dividida em quatro turnos de rega.

As sementes utilizadas de E. dunnii foram provenientes da empresa Mercosul Sementes Ltda. Foram usadas sementes peletizadas com o objetivo de facilitar a semeadura, pois o pequeno tamanho das sementes, em média $0,5 \mathrm{~mm}$, dificulta tal processo a partir do mesmo número sementes por tubete (Wendling \& Dutra, 2010). A peletização é um processo de recobrimento das sementes com material inerte e, em viveiros comerciais, o uso de uma única semente pode garantir uma plântula por tubete, não necessitando desbaste, diminuindo o custo pela perda de sementes e ressemeadura. Ainda assim, neste experimento, foram usadas duas sementes para garantir uma plântula por tubete, já que a germinação foi de $89,8 \%$ em um ensaio prévio à instalação do experimento. Para a semeadura de C. trichotoma foram utilizadas sementes de árvores matrizes, coletadas na área do campus da Universidade,

Tabela 1. Denominação dos substratos orgânicos e da classificação dos resíduos com baixa e alta relação C/N utilizados para compor as pilhas de compostagem.

Table 1. Denomination of organic substrates and the classification of waste with low and high $\mathrm{C} / \mathrm{N}$ ratio used to compose the compost piles.

\begin{tabular}{|c|c|c|}
\hline \multirow{2}{*}{$\begin{array}{l}\text { Denominação } \\
\text { dos substratos }\end{array}$} & \multicolumn{2}{|c|}{ Composição das pilhas de compostagem } \\
\hline & $\begin{array}{l}\text { Resíduos orgânicos com baixa relação } \mathrm{C} / \mathrm{N} \text {. } \\
\text { Fonte de nitrogênio }\end{array}$ & $\begin{array}{c}\text { Resíduos orgânicos com alta relação C/N. } \\
\text { Fonte de carbono } \\
{ }^{(2)}\end{array}$ \\
\hline RRU & $\begin{array}{l}\text { Resíduos orgânicos de restaurante universitário } \\
\text { (RRU). }\end{array}$ & Serragem \\
\hline RLD & $\begin{array}{l}\text { Resíduos orgânicos da reciclagem de lixo domi- } \\
\text { ciliar (RLD). }\end{array}$ & Serragem, palha de milho e soja \\
\hline DLB & $\begin{array}{l}\text { Dejeto líquido de bovinos (DLB), oriundo de } \\
\text { esterqueira de uma propriedade de produção de } \\
\text { leite. }\end{array}$ & Serragem \\
\hline LPF & $\begin{array}{l}\text { Lodo do processo de flotação (LPF) proveniente } \\
\text { de um frigorífico de frangos. }\end{array}$ & Serragem e palha de milho \\
\hline
\end{tabular}

(1) Relação C/N dos resíduos orgânicos: RRU = 15 (Loureiro et al., 2007); RLD = 7 a 21 (Cravo et al., 1998); DLB = 11 (Melo et al., 2008); $\mathrm{LPF}=2$ a 9 (Bernardi, 2011). ${ }^{(2)}$ Serragem $=865$ (Kiehl, 1985); palha de milho = 69 (Silva et al., 2008); palha de soja $=50$ (Abreu et al., 2011). 
Tabela 2. Atributos químicos e físicos dos substratos usados na produção de mudas de E. dunnii e C. trichotoma. Table 2. Chemical and physical attributes of the substrates used in the production of seedlings of E. dunnii and C. trichotoma.

\begin{tabular}{|c|c|c|c|c|c|}
\hline \multirow{2}{*}{ Parâmetros analisados } & \multicolumn{5}{|c|}{ Substratos $^{(1)}$} \\
\hline & RRU & RLD & DLB & LPF & SC \\
\hline Nitrogênio total $\left(\mathrm{g} \mathrm{kg}^{-1}\right)$ & 16,3 & 9,2 & 6,3 & 13,2 & 22,7 \\
\hline Carbono orgânico total $\left(\mathrm{g} \mathrm{kg}^{-1}\right)$ & 399,7 & 561,2 & 327,5 & 386,8 & 422,3 \\
\hline Relação C/N & 24,5 & 61,0 & 52,0 & 29,3 & 18,6 \\
\hline Nitrogênio mineral $\left(\mathrm{g} \mathrm{kg}^{-1}\right)$ & 2,10 & 0,37 & 0,13 & 0,50 & 0,12 \\
\hline Fósforo extraível $\left(\mathrm{mg} \mathrm{dm}^{-3}\right)$ & 76,1 & 47,9 & 101,5 & 76,0 & 41,0 \\
\hline Potássio trocável $\left(\mathrm{mg} \mathrm{dm}^{-3}\right)$ & 368,0 & 540,1 & 737,3 & 156,2 & 155,0 \\
\hline Cálcio trocável $\left(\mathrm{cmol}_{\mathrm{c}} \mathrm{dm}^{-3}\right)$ & 4,2 & 2,4 & 4,7 & 2,9 & 21,8 \\
\hline Magnésio trocável $\left(\mathrm{cmol}_{c} \mathrm{dm}^{-3}\right)$ & 1,1 & 0,8 & 2,3 & 0,5 & 10,4 \\
\hline $\mathrm{CTC}_{\mathrm{pH} 7,0}\left(\mathrm{cmol}_{\mathrm{c}} \mathrm{dm}^{-3}\right)$ & 8,2 & 5,6 & 9,8 & 5,4 & 36,2 \\
\hline Saturação por bases (\%) & 75,8 & 74,5 & 90,3 & 71,2 & 90,0 \\
\hline $\mathrm{pH}_{\text {água (1:1) }}$ & 6,5 & 6,8 & 6,6 & 6,9 & 6,1 \\
\hline Argila $\left(\mathrm{g} \mathrm{dm}^{-3}\right)$ & 11,3 & 7,3 & 7,3 & 7,7 & 3,0 \\
\hline Umidade $65^{\circ} \mathrm{C}\left(\%_{\mathrm{m} / \mathrm{m}}\right)$ & 12,3 & 19,4 & 7,1 & 5,7 & 21,5 \\
\hline Densidade aparente $\left(\mathrm{Mg} \mathrm{m}^{-3}\right)$ & 0,41 & 0,37 & 0,40 & 0,32 & 0,33 \\
\hline
\end{tabular}

${ }^{(1)}$ RRU: resíduos de restaurante universitário; RLD: resíduos da reciclagem de lixo domiciliar; DLB: dejeto líquido de bovinos; LPF: lodo do processo de flotação; SC: substrato comercial.

com percentual de germinação de $67,3 \%$. As sementes apresentam em média $0,85 \mathrm{~cm}$ de comprimento e 0,45 cm de largura (Felippi et al., 2012), tamanho que facilita a semeadura nos tubetes sem a necessidade de peletização.

A avaliação da germinação das plântulas iniciou-se aos 20 dias após a semeadura (DAS) e, posteriormente, em intervalos de sete dias até a estabilização da germinação. Aos 92 DAS foi avaliada a altura das mudas $(\mathrm{H})$, medindo-se a distância do colo até as últimas axilas foliares, e o diâmetro do colo (DC) mensurado com paquímetro digital. Com base nos resultados obtidos, foi calculada a relação H/DC, que exprime o equilíbrio de crescimento das mudas no viveiro (Carneiro, 1995).

Os dados foram submetidos à análise de variância e as médias de tratamentos comparadas pelo teste de Tukey a 5\% de probabilidade de erro. Para a análise estatística foi utilizado o programa Sisvar 5.3 (Ferreira, 2011).

\section{RESULTADOS E DISCUSSÃO}

A análise estatística evidenciou interação significativa $(\mathrm{p} \leq 0,05)$ entre as espécies vegetais e os substratos para todas as variáveis analisadas, exceto o percentual de germinação aos 34 e 41 DAS (Tabela 3). Isto mostra que os substratos interferiram de forma diferente no crescimento e na qualidade das mudas nas duas espécies florestais.

As diferenças no percentual de germinação entre os substratos, tanto no E. dunnii como no C. trichotoma, foram maiores nas primeiras avaliações realizadas após a semeadura, diminuindo nas avalições subsequentes (Tabela 4). Observa-se que a estabilização da germinação iniciou-se a partir dos 27 DAS no E. dunnii com o RRU e RLD, enquanto nos demais substratos a estabilização ocorreu a partir dos 34 DAS nas duas espécies florestais.

As características físicas dos substratos são parâmetros que podem interferir diretamente na germinação das sementes. A variação dos valores de densidade dos substratos de 0,32 a $0,41 \mathrm{Mg} \mathrm{m}^{-3}$ (Tabela 2) pode ter afetado a disponibilidade de oxigênio, comprometendo a germinação das sementes, pois a densidade do substrato é inversamente relacionada com a porosidade e, dessa maneira, pode ocorrer maior retenção de água à medida que a densidade aumenta (Barbosa et al., 1985). Destacase que a constituição física do substrato é determinante na produção de mudas (Rebouças et al., 2008), pois a capacidade de absorção de água pelas sementes depende da retenção de água e da aeração do substrato (Pozitano \& Rocha, 2011), que é afetado pelo equilíbrio entre a macro e a microporosidade, principalmente 
em sistemas de produção de mudas em pequenos recipientes (Lopes et al., 2005).

No E. dunnii, os maiores valores de densidade nos RRU, RLD e DLB (Tabela 2) contribuíram com maior número de plântulas germinadas aos 20 DAS (Tabela 4), indicando maior velocidade de germinação. No C. trichotoma, os mesmos substratos contribuíram com menor velocidade de germinação. De acordo com Guerrini \& Trigueiro (2004), substratos formados à base de resíduos orgânicos apresentam predominância de microporos em detrimento dos macroporos. Consequentemente, acumulam maior volume de água e, dependendo da espécie, pode afetar o processo de germinação. Provavelmente, a maior retenção de

Tabela 3. Probabilidade do teste F, média e coeficiente de variação (CV) do percentual de germinação (PG) aos 20, 27, 34 e 41 dias após a semeadura (DAS), diâmetro do colo (DC), altura (H) e relação entre H/DC das mudas das espécies florestais em diferentes substratos.

Table 3. Probability of F-test, mean and coefficient of variation (CV) of the germination percentage (PG) at 20, 27, 34 and 41 days after sowing (DAS), stem diameter (DC), height (H) and relationship H/DC of forest species seedlings in different substrates.

\begin{tabular}{|c|c|c|c|c|c|}
\hline \multirow{3}{*}{ Avaliações } & \multicolumn{3}{|c|}{ Probabilidade do teste F } & \multirow{3}{*}{ Média } & \multirow{3}{*}{$\begin{array}{l}\text { CV } \\
(\%)\end{array}$} \\
\hline & \multicolumn{2}{|c|}{ Fatores principais } & \multirow{2}{*}{$\begin{array}{c}\text { Interação } \\
(E \times S)\end{array}$} & & \\
\hline & Espécies (E) & Substratos (S) & & & \\
\hline PG (\%) - 20 DAS & $0,0000^{*}$ & 0,5636 & $0,0000^{*}$ & 42,2 & 23,4 \\
\hline PG (\%) - 27 DAS & $0,0060^{*}$ & 0,3557 & $0,0025^{\star}$ & 67,5 & 16,6 \\
\hline PG (\%) - 34 DAS & $0,0000^{*}$ & 0,5033 & 0,2533 & 74,1 & 13,5 \\
\hline PG (\%) - 41 DAS & $0,0000^{*}$ & 0,5033 & 0,2533 & 74,1 & 13,5 \\
\hline $\mathrm{DC}(\mathrm{mm})$ & $0,0000^{\star}$ & $0,0000^{*}$ & $0,0226^{*}$ & 1,4 & 15,7 \\
\hline $\mathrm{H}(\mathrm{cm})$ & $0,0000^{*}$ & $0,0000^{*}$ & $0,0000^{*}$ & 6,2 & 23,2 \\
\hline $\mathrm{H} / \mathrm{DC}$ & $0,0000^{*}$ & $0,0266^{*}$ & $0,0306^{*}$ & 4,9 & 22,6 \\
\hline
\end{tabular}

${ }^{*}$ Teste $\mathrm{F}$ significativo $(\mathrm{p} \leq 0,05)$.

Tabela 4. Percentagem de germinação das sementes de E. dunnii e C. trichotoma em substratos de compostagem de resíduos orgânicos e em substrato comercial.

Table 4. Percentage of seed germination of E. dunnii and C. trichotoma in substrates from composting of organic waste and commercial substrate.

\begin{tabular}{|c|c|c|c|c|c|c|}
\hline \multirow{2}{*}{ Espécies } & \multicolumn{6}{|c|}{ Substratos ${ }^{(1)}$} \\
\hline & RRU & RLD & DLB & LPF & SC & $\mathrm{SC}+\mathrm{NPK}$ \\
\hline & \multicolumn{6}{|c|}{20 dias após a semeadura } \\
\hline E. dunnii & $71,9 \mathrm{aAB}{ }^{(2)}$ & $78,1 \mathrm{aA}$ & $59,4 \mathrm{aABC}$ & $53,1 \mathrm{aBC}$ & $50,0 \mathrm{aC}$ & $43,8 \mathrm{aC}$ \\
\hline C. trichotoma & $11,1 \mathrm{bB}$ & $11,1 \mathrm{bB}$ & $33,3 \mathrm{bA}$ & $22,2 \mathrm{bAB}$ & $30,5 \mathrm{bAB}$ & $41,7 \mathrm{aAB}$ \\
\hline \multirow[t]{2}{*}{ Média } & 41,5 & 44,6 & 46,4 & 43,2 & 40,3 & 42,8 \\
\hline & \multicolumn{6}{|c|}{27 dias após a semeadura } \\
\hline E. dunnii & $87,5 \mathrm{aAB}$ & $90,6 \mathrm{aA}$ & $78,1 \mathrm{aAB}$ & $78,1 \mathrm{aAB}$ & $4,4 \mathrm{aAB}$ & $65,6 \mathrm{aB}$ \\
\hline C. trichotoma & $50,0 \mathrm{bAB}$ & $36,1 \mathrm{bB}$ & $55,6 \mathrm{bAB}$ & $63,9 \mathrm{aA}$ & $61,1 \mathrm{aA}$ & $58,3 \mathrm{aAB}$ \\
\hline \multirow[t]{2}{*}{ Média } & 68,8 & 63,4 & 66,9 & 71,0 & 72,8 & 62,0 \\
\hline & \multicolumn{6}{|c|}{34 dias após a semeadura } \\
\hline E. dunnii & 87,5 & 90,6 & 81,3 & 84,4 & 90,6 & 75,0 \\
\hline C. trichotoma & 61,1 & 55,6 & 67,0 & 66,7 & 65,0 & 63,9 \\
\hline \multirow[t]{2}{*}{ Média } & $74,3 \mathrm{~A}$ & $73,1 \mathrm{~A}$ & $74,2 \mathrm{~A}$ & $75,6 \mathrm{~A}$ & $77,8 \mathrm{~A}$ & $69,5 \mathrm{~A}$ \\
\hline & \multicolumn{6}{|c|}{41 dias após a semeadura } \\
\hline E. dunnii & 87,5 & 90,6 & 81,3 & 84,4 & 90,6 & 75,0 \\
\hline C. trichotoma & 61,1 & 55,6 & 67,0 & 66,7 & 65,0 & 63,9 \\
\hline Média & $74,3 \mathrm{~A}$ & $73,1 \mathrm{~A}$ & $74,2 \mathrm{~A}$ & $75,6 \mathrm{~A}$ & $77,8 \mathrm{~A}$ & $69,5 \mathrm{~A}$ \\
\hline
\end{tabular}

${ }^{(1)} \mathrm{RRU}$ : resíduos de restaurante universitário; RLD: resíduos de reciclagem de lixo domiciliar; DLB: dejeto líquido de bovinos, LPF: lodo do processo de flotação; SC: substrato comercial; SC + NPK: substrato comercial com fertilizante NPK. ${ }^{(2)}$ Médias não seguidas pela mesma letra, minúscula na coluna e maiúscula na linha, diferem pelo teste de Tukey a 5\% de probabilidade de erro. 
água nos substratos com maior densidade (RRU, RLD e DLB) diminuiu a disponibilidade de oxigênio no início do processo de germinação e afetou com maior intensidade as sementes do C. trichotoma, que apresentaram menor velocidade de germinação. Apesar da diferença na velocidade de germinação entre os substratos nas duas espécies florestais, não houve diferença significativa após a estabilização da germinação (34 e 41 DAS) (Tabela 4).

Observa-se que o percentual de germinação após a estabilização (41 DAS) alcançou valores médios de 84,9 e 63,2\% no E. dunnii e C. trichotoma, respectivamente (Tabela 4), semelhante ao ensaio prévio à instalação do experimento que apresentou 89,8 e $67,3 \%$ de germinação, respectivamente, para as duas espécies florestais. A diferença no percentual de germinação entre as espécies deve estar relacionada às suas características intrínsecas, como tamanho, qualidade das sementes, manejo de coleta e pós-coleta (Silva et al., 2003). Os mesmos autores ainda destacam que mesmo em sementes da mesma planta matriz o processo germinativo pode ser afetado pelo tamanho das sementes.

$\mathrm{O}$ crescimento das mudas avaliado pela altura e diâmetro do colo apresentou diferença significativa entre os substratos nas duas espécies florestais, com maior valor para o SC com o uso do fertilizante mineral (Tabela 5). Na ausência de fertilizante mineral, as diferenças de crescimento das mudas entre os substratos foram significativas somente no $E$. dunnii, com variação de 2,3 a 9,1 cm na altura e 0,4 a 1,1 mm no diâmetro do colo. Em um estudo com duas espécies florestais, Kratz et al. (2013) observaram que a variação dos atributos físicos e químicos dos substratos não afetou o crescimento das mudas de E. benthamii, semelhante aos resultados obtidos com o $C$. trichotoma, no presente estudo. Os autores ressaltam que o crescimento diferenciado nas mudas de Mimosa scabrella foi atribuído à variação da densidade, da matéria orgânica, do $\mathrm{pH}$, da condutividade elétrica e da salinidade dos substratos. Variações no crescimento de mudas entre substratos também são encontradas em outras espécies florestais, como destacam Melo et al. (2014) usando combinações de esterco de curral curtido, casca de arroz carbonizada e fibra de coco com $10 \%$ de vermiculita na produção de mudas de E. grandis e Eremanthus erythropappus, e Delarmelina et al. (2014), com substratos de lodo de esgoto, fibra de coco, vermiculita e casca de arroz, na produção de mudas de Sesbania virgata.

A maior altura e diâmetro do colo das mudas no E. dunnii foram encontrados nos substratos com as menores relações $\mathrm{C} / \mathrm{N}$ e com os maiores teores de nitrogênio total (RRU, LPF e SC) (Tabelas 2 e 5). Nesses substratos, a relação $\mathrm{C} / \mathrm{N}$ foi entre 18,6 e 29,3, e os teores de nitrogênio total variaram entre 13,2 e 22,7 $\mathrm{g} \mathrm{kg}^{-1}$. A variação na relação $\mathrm{C} / \mathrm{N}$ e nos teores de nitrogênio entre os substratos provavelmente esteja relacionada aos materiais utilizados no processo de compostagem e à quantidade de matéria seca presente no resíduo orgânico fornecedor de nitrogênio (Tabela 1). Nas pilhas

Tabela 5. Altura, diâmetro do colo e relação H/DC das mudas de E. dunnii e C. trichotoma aos 92 dias após a semeadura em substratos de compostagem de resíduos orgânicos e em substrato comercial.

Table 5. Height, stem diameter and H/DC of seedlings of E. dunnii and C. trichotoma evaluated at 92 days after sowing in composting substrates of organic waste and commercial substrate.

\begin{tabular}{|c|c|c|c|c|c|c|}
\hline \multirow{2}{*}{ Espécies } & \multicolumn{6}{|c|}{ Substratos ${ }^{(1)}$} \\
\hline & RRU & RLD & DLB & LPF & SC & SC + NPK \\
\hline & \multicolumn{6}{|c|}{ Altura $(\mathrm{H})(\mathrm{cm})$} \\
\hline E. dunnii & $5,3 \mathrm{aC}^{(2)}$ & $3,3 \mathrm{aCD}$ & $2,3 \mathrm{aD}$ & $4,7 \mathrm{Ac}$ & $9,1 \mathrm{aB}$ & $24,0 \mathrm{aA}$ \\
\hline \multirow[t]{2}{*}{ C. trichotoma } & $3,8 \mathrm{aB}$ & $3,7 \mathrm{aB}$ & $2,1 \mathrm{aB}$ & $3,1 \mathrm{aB}$ & $2,5 \mathrm{bB}$ & $9,0 \mathrm{bA}$ \\
\hline & \multicolumn{6}{|c|}{ Diâmetro do colo (DC) (mm) } \\
\hline E. dunnii & $0,8 \mathrm{bBC}$ & $0,6 \mathrm{bC}$ & $0,4 \mathrm{bC}$ & $0,7 \mathrm{bBC}$ & $1,1 \mathrm{aB}$ & $2,8 \mathrm{bA}$ \\
\hline \multirow[t]{2}{*}{ C. trichotoma } & $1,2 \mathrm{aB}$ & $1,2 \mathrm{aB}$ & $1,2 \mathrm{aB}$ & $1,6 \mathrm{aB}$ & $1,3 \mathrm{aB}$ & $3,8 \mathrm{aA}$ \\
\hline & \multicolumn{6}{|c|}{$\mathrm{H} / \mathrm{DC}$} \\
\hline E. dunnii & $6,6 \mathrm{aAB}$ & $5,5 \mathrm{aB}$ & $5,7 \mathrm{aB}$ & $6,7 \mathrm{aAB}$ & $8,3 \mathrm{aA}$ & $8,6 \mathrm{aA}$ \\
\hline C. trichotoma & $3,2 \mathrm{bA}$ & $2,6 \mathrm{bA}$ & $1,8 \mathrm{bA}$ & $1,9 \mathrm{bA}$ & $1,9 \mathrm{bA}$ & $2,4 \mathrm{bA}$ \\
\hline
\end{tabular}

${ }^{(1)}$ RRU: resíduos do restaurante universitário; RLD: resíduos da reciclagem de lixo domiciliar; DLB: dejeto líquido de bovino; LPF: lodo do processo de flotação; SC: substrato comercial. ${ }^{(2)}$ Médias não seguidas pela mesma letra, minúsculas na coluna e maiúscula na linha, dentro de cada parâmetro, diferem pelo teste de Tukey a 5\% de probabilidade de erro. 
de compostagem foram utilizados aproximadamente $30 \%$ do volume do resíduo orgânico como fonte de nitrogênio (baixa relação $\mathrm{C} / \mathrm{N}$ ) e, provavelmente, nos materiais com menor massa seca, como nos dejetos líquidos (DLB), foi adicionada uma menor quantidade de nitrogênio.

A relação $\mathrm{C} / \mathrm{N}$ é um parâmetro importante para caracterizar o substrato, pois indica a forma como os materiais orgânicos se encontram no final do processo de compostagem. A instrução normativa $\mathrm{n}^{\circ} 25$ do Ministério de Agricultura, Pecuária e Abastecimento (Brasil, 2009) destaca que a relação $\mathrm{C} / \mathrm{N}$ não pode ultrapassar a 20 e o teor de nitrogênio total deve ser no mínimo de 5,0 $\mathrm{g} \mathrm{kg}^{-1}$ para compostos orgânicos. Apesar do RRU e LPF apresentarem relação $\mathrm{C} / \mathrm{N}$ de 24,5 e 29,3 , respectivamente, os valores foram mais próximos à mínima recomendada pela normativa em relação aos substratos provenientes de RLD e DLB (relação $\mathrm{C} / \mathrm{N}$ de 61,0 e 52,0, respectivamente).

A menor relação $\mathrm{C} / \mathrm{N}$ no $\mathrm{SC}(18,6)$ e nos substratos provenientes da compostagem (RRU e LPF) provavelmente contribuiu para o maior crescimento das mudas de E. dunnii devido à maior disponibilidade de nitrogênio proveniente da mineralização da fração orgânica que, segundo Pereira (2013), apresenta relação inversa entre a relação $\mathrm{C} / \mathrm{N}$ e a disponibilidade de nitrogênio no substrato. Nos substratos com elevada relação C/N (RLD e DLB), provavelmente a baixa disponibilidade de nitrogênio devido à imobilização do nutriente pelos microrganismos no processo de decomposição dos resíduos orgânicos tenha sido o fator que afetou o crescimento das mudas de E. dunnii (Andreani et al., 2011).

$\mathrm{O}$ pH adequado dos substratos (mínimo de 6,0), conforme a normativa do Brasil (2009), associado à adequada saturação por bases e teores igualmente adequados de fósforo, potássio, cálcio e magnésio (Tabela 2), com base nos valores da CQFS-RS/SC (2004), também foram atributos químicos que provavelmente contribuíram para o maior crescimento das mudas do E. dunnii nos substratos com menor relação $\mathrm{C} / \mathrm{N}$. Normalmente, as mudas de rápido crescimento inicial demandam maior quantidade de nutrientes (Santos et al., 2008), possibilitando maiores diferenças em função dos atributos químicos dos substratos, justificando as diferenças significativas somente nas mudas do E. dunnii.
A altura e o diâmetro do colo das mudas do C. trichotoma com o uso de fertilizante mineral no SC atingiram $9,0 \mathrm{~cm}$ e $3,8 \mathrm{~mm}$, respectivamente, semelhante aos valores encontrados por Malavasi \& Malavasi (2003) aos 70 dias após a repicagem, usando SC com adubações NPK em cobertura. No E. dunnii, a altura e o diâmetro do colo das mudas com o uso de fertilizante mineral chegaram a $24,0 \mathrm{~cm}$ e $2,8 \mathrm{~mm}$, respectivamente, valores superiores aos encontrados por Kratz \& Wendling (2013), aos 90 dias da semeadura com uso de fertilizante de liberação lenta (15-10-10), em dois substratos comerciais e em 12 substratos alternativos, com combinações variadas de casca de arroz carbonizada, casca de pinus, fibra de coco e vermiculita.

Comparando o SC sem e com fertilizante mineral, o incremento foi de 6,5 e $14,9 \mathrm{~cm}$ em altura e de 2,5 e 1,7 mm em diâmetro do colo no C. trichotom e E. dunnii, respectivamente. Esses resultados mostram a necessidade de fertilização mineral no SC e indica necessidade de fertilização também nos substratos de compostagem de resíduos orgânicos (RRU, RLD, DLB e LPF), pois estes foram iguais ou inferiores ao SC sem o fertilizante mineral (Tabela 5). Apesar disso, o maior crescimento das mudas nos substratos alternativos de RRU e LPF, utilizados na ausência de fertilizante mineral, pode representar redução da necessidade de fertilização e contribuir para a redução de custo de produção.

Salazar et al. (2005) destacam que o pequeno volume dos tubetes não comporta quantidade de substrato suficiente para atender a demanda de nutrientes para as mudas, principalmente em condições irrigadas com várias aspersões diárias. Assim, são necessárias adições de fertilizantes via irrigação ou o uso de fertilizantes de liberação lenta, que promove uma liberação homogênea dos nutrientes durante o período de produção das mudas (Scivittaro et al., 2004) associada a substratos que apresentam características físicas adequadas (Melo et al., 2014). Destaca-se que com o uso do fertilizante mineral as mudas de E. dunnii atingiram a altura e o diâmetro do colo mínino para o plantio no campo, que são de $15 \mathrm{~cm}$ e $2 \mathrm{~mm}$, respectivamente (Wendling \& Dutra, 2010).

A qualidade das mudas do E. dunnii medida pela relação entre altura e diâmetro do colo (H/DC) foi entre 5,5 e 6,7 nos substratos alternativos, sem adubação 
mineral (RRU, RLD, DLB e LPF), e de 8,3 e 8,6 no SC, sem e com fertilizante mineral, respectivamente (Tabela 5). Observa-se que os valores estão dentro da faixa ideal recomendada por Carneiro (1995) para as espécies de eucalipto, que variam entre 5,4 e 8,1. No entanto, Kratz \& Wendling (2013) salientam que a relação H/DC para o eucalipto tende a ser superior a 8,0 , mostrando necessidade de rever os valores ideais para essa espécie.

A relação $\mathrm{H} / \mathrm{DC}$ das mudas do $C$. trichotoma foi entre 1,8 e 3,2, e mostra a necessidade de um maior período de tempo para atingir a relação ideal para plantio no campo, confirmando o crescimento inicial lento dessa espécie (Carvalho, 2002). Vallone et al. (2009) destacam que deve-se ter cuidado ao se referir à qualidade das mudas com base na relação H/DC, pois nem sempre o substrato que proporciona o maior crescimento das mudas no viveiro é responsável pelo maior crescimento após o transplante. Isto ressalta a importância de, em futuros trabalhos, incluir a quantificação da massa seca da parte aérea e radicular para avaliar a qualidade das mudas com base no cálculo do índice de qualidade de Dickson (IQD)

A produção de mudas de E. dunnii no período de 92 dias, apesar de apresentarem relação H/DC dentro o ideal, indica que a altura foi significativamente inferior nos substratos sem fertilização mineral, não permitindo produzir mudas com altura adequada para transplante. No C. trichotoma, o período de tempo não foi suficiente para produzir mudas com qualidade adequada e nem mesmo com tamanho adequado para o plantio. Isso indica um maior período de tempo para a produção de mudas de $C$. trichotoma e reforça a necessidade de fertilização mineral com uso de tubetes nas duas espécies florestais. Independente disso, o maior crescimento das mudas nos substratos alternativos de RRU e LPF mostra potencial de uso em substituição ao SC nas duas espécies florestais.

\section{CONCLUSÕES}

O substrato comercial quando acrescido com fertilizante de liberação lenta proporciona maior crescimento em altura e em diâmetro do colo nas mudas das duas espécies florestais.

Os substratos provenientes de resíduos de restaurante universitário e lodo de processo de flotação, quando associado ao uso de fertilizante mineral, podem ser utilizados na produção de mudas de E. dunnii e C. trichotoma em substituição ao substrato comercial.

\section{STATUS DA SUBMISSÃO}

Recebido: 6 out., 2014

Aceito: 7 jul., 2015

\section{AUTOR(ES) PARA CORRESPONDÊNCIA}

\section{Clovis Orlando Da Ros}

Departamento de Ciências Agronômicas e

Ambientais, Universidade Federal de Santa Maria

- UFSM, Campus de Frederico Westphalen, Linha 7 de Setembro, s/n, BR 386, Km 40, CP 54, CEP 98400-000, Frederico Westphalen, RS, Brasil e-mail: clovisdaros@gmail.com

\section{REFERÊNCIAS}

Abad M, Martinez PF, Martinez J. Evaluación agrónomica de los substratos de cultivo. Actas de Horticultura 1992; 11: 141-154.

Abad M, Noguera P, Carrión C. Sustratos para el cultivo sin suelo y fertirrigación. In: Cadahía C, coordenador. Fertirrigación, cultivos hortícolas, frutales y ornamentales. Madrid: Mundi-Prensa; 2005.

Abreu PG, Paiva DP, Abreu VMN, Coldebella A, Cestonaro T. Casca de arroz e palhada de soja na compostagem de carcaças de frangos de corte. Acta Scientiarum. Animal Science 2011; 33(1): 51-57.

Alvares CA, Stape JL, Sentelhas PC, de Moraes Gonçalves JL, Sparovek G. Köppen's climate classification map for Brazil. Meteorologiesche Zeitschrift 2013; 22(6): 711-728. http://dx.doi.org/10.1127/0941-2948/2013/0507.

Andreani R Jr, Andreani DIK, Luison EA, Silva EG, Gimenez JI. Diferentes compostos orgânicos como substratos para produção de mudas de tomate. Revista Pesquisa em Foco 2011; 19(1): 42-52.

Associação Brasileira de Normas Técnicas - ABNT. NBR 10.007: resíduos sólidos: classificação. São Paulo; 2004.

Barbosa JMF, Barbosa LMM, Pinto MM. Influência do substrato, da temperatura e do armazenamento, sobre a germinação de sementes de quatro espécies nativas. Revista Brasileira de Sementes 1985; 10(1): 46-54.

Bernardi FH. Uso do processo de compostagem no aproveitamento de resíduos de incubatório e outros de origem agroindustrial [dissertação]. Cascavel: Universidade Estadual do Oeste do Paraná; 2011. 
Brasil. Ministério de Agricultura Pecuária e Abastecimento - MAPA. Instrução Normativa no 25, de 23 de julho de 2009. Diário Oficial da República Federativa do Brasil, Brasília, DF (2009 jul. 28); Sec. 1.

Carneiro JGA. Produção e controle de qualidade de mudas florestais. Curitiba: UENF; 1995.

Carvalho PER. Louro Pardo: taxonomia. Colombo: EMBRAPA Florestas; 2002. Circular Técnica n. 66.

Comissão de Química e Fertilidade do Solo - CQFS-RS/ SC. Manual de adubação e de calagem para os Estados do Rio Grande do Sul e de Santa Catarina. 10. ed. Porto Alegre: Sociedade Brasileira de Ciência do Solo-Núcleo Regional Sul; 2004.

Correia MCR, Pinheiro MCB, Lima HA. Produção de frutos e germinação de sementes de Amemopaegma chamberlaynii Bur. \& K. Schum. (Bignoniaceae): um registro de poliembrionia. Sitientibus Série Ciências Biológicas 2005; 5(2): 68-71.

Cravo MS, Muraoka T, Giné MF. Caracterização química de compostos de lixo urbano de algumas usinas brasileiras. Revista Brasileira de Ciencia do Solo 1998; 22(3): 547-553. http://dx.doi.org/10.1590/S0100-06831998000300021.

Cunha AO, Andrade LA, Bruno RLA, Silva JAL, Souza VC. Efeitos de substratos e das dimensões dos recipientes na qualidade das mudas de Tabebuia impetiginosa (Mart. Ex D.C.) Standl. Revista Árvore 2005; 29(4): 507-516. http://dx.doi.org/10.1590/S0100-67622005000400002.

Cunha-Queda C, Morais MC, Ribeiro HM, Almeida MH. Caracterização de compostos e de materiais orgânicos para a formulação de substratos para viveiros. Revista de Ciências Agrárias 2010; 33(1): 367-375.

Delarmelina WM, Caldeira MVW, Faria JCT, Gonçalves EO, Rocha RLF. Diferentes substratos para a produção de mudas de Sesbania virgata. Floresta e Ambiente 2014; 21(2): 224-233. http://dx.doi.org/10.4322/floram.2014.027.

Empresa Brasileira de Pesquisa Agropecuária - EMBRAPA. Manual de métodos de análise de solos. 2. ed. Rio de Janeiro: EMBRAPA-CNPS; 1997.

Empresa Brasileira de Pesquisa Agropecuária - EMBRAPA. Zoneamento ecológico para plantios florestais no Estado de Santa Catarina. Curitiba: EMBRAPA-CNPF; 1988.

Felippi M, Maffra CRB, Cantarelli EB, Araújo MM, Longhi SJ. Fenologia, morfologia e análise de sementes de Cordia trichotoma (Vell.) Arráb. ex Steud. Ciência Florestal 2012; 22(3): 631-641.

Ferreira DF. Sisvar: a computer statistical analysis system. Ciência e Agrotecnologia 2011; 35(6): 1039-1042.

Gomes LAA, Rodrigues AC, Collier LS, Feitosa SS. Produção de mudas de alface em substrato alternativo com adubação. Horticultura Brasileira 2008; 26(3): 359-363. http://dx.doi.org/10.1590/S0102-05362008000300013.
Gonçalves EO, Petri GM, Caldeira MVW, Dalmaso TT, Silva AG. Crescimento de mudas de Ateleia glazioviana em substratos contendo diferentes materiais orgânicos. Revista Floresta e Ambiente 2014; 21(3): 339-348. http:// dx.doi.org/10.1590/2179-8087.029213.

Guerrini IA, Trigueiro RM. Atributos físicos e químicos de substratos compostos por biossólidos e casca de arroz carbonizada. Revista Brasileira de Ciencia do Solo 2004; 28(6): 1069-1076. http://dx.doi.org/10.1590/S010006832004000600016.

Kiehl JE. Fertilizantes orgânicos. Piracicaba: Editora Agronômica Ceres; 1985.

Kostopoulou P, Radoglou K, Kini PO, Adamidou C. Effect of mini-plug container depth on root and shoot growth of four forest tree species during early developmental stages. Turkish Journal of Agriculture and Forestry 2011; 35: 379-390.

Kratz D, Wendling I, Nogueira AC, Souza PVD. Utilização de resíduos urbanos e agroflorestais para produção de mudas de Eucalyptus benthamii e Mimosa scabrella. Floresta e Ambiente 2013; 20(4): 530-537.

Kratz D, Wendling I. Produção de mudas de Eucalyptus dunnii em substratos renováveis. Revista Floresta 2013; 43(1): 125-136. http://dx.doi.org/10.5380/rf.v43i1.25989.

Lopes JLW, Guerrini IA, Saad JCC, Silva MR. Efeitos da irrigação na sobrevivência, transpiração e no teor relativo de água na folha em mudas de Eucalyptus grandis em diferentes substratos. Scientia Forestalis 2005; 68: 97-106.

Loureiro DC, Aquino AM, Zonta E, Lima E. Compostagem e vermicompostagem de resíduos domiciliares com esterco bovino para a produção de insumo orgânico. Pesquisa Agropecuaria Brasileira 2007; 42(7): 1043-1048. http:// dx.doi.org/10.1590/S0100-204X2007000700018.

Malavasi UC, Malavasi MM. Efeito do tubete no crescimento inicial de Cordia trichotoma (Vell) Arrab. Ex steud e Jacaranda micranta Cham. Revista Ciência Exatas e Naturais 2003; 5(2): 211-218.

Melo LA, Pereira GA, Moreira EJC, Davide AC, Silva EV, Teixeira LAF. Crescimento de mudas de Eucalyptus grandis e Eremanthus rythropappus sob diferentes formulações de substrato. Floresta e Ambiente 2014; 21(2): 234-242. http://dx.doi.org/10.4322/floram.2014.028.

Melo LCA, Silva CA, Dias BO. Caracterização da matriz orgânica de resíduos de origens diversificadas. Revista Brasileira de Ciencia do Solo 2008; 32(1): 101-110. http:// dx.doi.org/10.1590/S0100-06832008000100010.

Oliveira RB, Lima JSS, Souza CAM, Silva SA, Martins S Fo. Produção de mudas de essências florestais em diferentes substratos e acompanhamento do desenvolvimento em campo. Ciência e Agrotecnologia 2008; 32(1): 122-128. http://dx.doi.org/10.1590/S1413-70542008000100018. 
Paludzyszyn E Fo, Santos PET, Ferreira CA. Eucaliptos indicados para plantio no Estado do Paraná. Colombo: EMBRAPA Florestas; 2006. Documentos n. 129.

Pereira MS. Mineralização do resíduo da pupunheira em condições de campo e laboratório [dissertação]. Viçosa: Universidade Federal de Viçosa; 2013.

Pozitano M, Rocha CSJ. Caracterização física e germinação de sementes de Senna macranthera. Revista Brasileira Sementes 2011; 33(4): 777-784.

Rebouças ER, Gentil DFO, Ferreira SAN. Caracterização física de frutos e sementes de goiaba da Costa-Rica, produzidos em Manaus, Amazonas. Revista Brasileira de Fruticultura 2008; 30(2): 546-548. http://dx.doi. org/10.1590/S0100-29452008000200048.

Salazar FJ, Chadwick D, Pain BF, Hatch D, Owen E. Nitrogen budgets for three cropping systems fertilised with cattle manure. Bioresource Technology 2005; 96(2): 235-245. http://dx.doi.org/10.1016/j.biortech.2004.05.013. PMid:15381222.

Santos JZL, Resende AV, Furtini AE No, Corte EF. Crescimento, acúmulo de fósforo e frações fosfatadas em mudas de sete espécies arbóreas nativas. Revista Árvore 2008; 32(5): 799-807. http://dx.doi.org/10.1590/S010067622008000500003.

Scheeren LW, Schneider PSP, Schneider PR, Finger CAG. Crescimento do louro-pardo, Cordia trichotoma (Vell.) Arrab. ex Steud., na Depressão Central do estado do Rio Grande do Sul. Revista Ciência Florestal 2002; 12(2): 169-176.
Scivittaro WB, Oliveira RPD, Radmann EB. Doses de fertilizantes de liberação lenta na formação de porta enxerto de 'trifoliata'. Revista Brasileira de Fruticultura 2004; 26(3): 520-523. http://dx.doi.org/10.1590/S010029452004000300035 .

Silva CV, Bilia DAC, Maluf AM, Barbedo CJ. Fracionamento e germinação de sementes de uvaia (Eugenia pyriformis Cambess. - Myrtaceae). Revista Brasileira de Botanica 2003; 26(2): 213-221. http://dx.doi.org/10.1590/S010084042003000200009 .

Silva ECl, Muraoka TB, Salatiér E, Freddy SC, Trivelin PCO. Utilização do nitrogênio da palha de milho e de adubos verdes pela cultura do milho. Revista Brasileira de Ciência do Solo 2008; 32(spe): 2853-2861.

Sturion JA, Antunes BMA. Produção de mudas de espécies florestais. In: Galvão APM. Reflorestamento de propriedades rurais para fins de produtivos e ambientais: um guia para ações municipais e regionais. Colombo: EMBRAPA Florestas; 2000.

Tedesco MJ, Gianello C, Bissani CA, Bohnen H, Volkweiss SJ. Análises de solos, plantas e outros materiais. 2. ed. Porto Alegre: UFRGS; 1995.

Vallone HS, Guimarães RJ, Mendes ANG, Souza CAS, Dias FP, Carvalho AM. Recipientes e substratos na produção de mudas e no desenvolvimento inicial de cafeeiros após o plantio. Ciência e Agrotecnologia 2009; 33(5): 1327-1335. http://dx.doi.org/10.1590/S1413-70542009000500019.

Wendling I, Dutra LF. Produção de mudas de eucalipto por sementes. In: Wendling I, Dutra LF. Produção de mudas de eucalipto. Colombo: EMBRAPA Florestas; 2010. 